\title{
Crescimento, acúmulo de íons e produção de tomateiro irrigado com água salina ${ }^{1}$
}

\section{Growth, ion accumulation and yield of tomato plants irrigated with saline water}

\author{
Antonio Lucineudo de Oliveira Freire ${ }^{2 *}$; Vlaminck Paiva Saraiva ${ }^{3}$; \\ José Romilson Paes de Miranda ${ }^{4}$ Genildo Bandeira Bruno ${ }^{5}$
}

\section{Resumo}

O tomateiro (Lycopersicon esculentum Mill.) é uma das hortaliças mais consumidas no mundo. No Estado da Paraíba, sua produtividade encontra-se abaixo da média nacional e a salinidade é um dos fatores que têm contribuído para isso. Esse trabalho teve como objetivo avaliar os efeitos da salinidade no crescimento, na nutrição mineral e na produção de duas cultivares de tomateiro rasteiro. Foram estudadas as cultivares Santa Adélia e Meia Estaca, irrigadas com água apresentando condutividades elétricas de 0,$4 ; 1,5 ; 3,0 ; 4,5$ e $6,0 \mathrm{dS} \mathrm{m}^{-1}$, constituindo um fatorial $2 \times 5$, com 3 repetições. Analisaram-se a massa seca da parte aérea e das raízes, a taxa de crescimento relativo, os teores foliares de $\mathrm{N}, \mathrm{K}, \mathrm{Ca}$, $\mathrm{Mg}, \mathrm{S}$ e Na, e a produção de frutos. Observou-se que a salinidade reduziu a massa seca da parte aérea nas plantas da cultivar Santa Adélia. As cultivares apresentaram comportamento diferenciado quanto aos teores dos nutrientes nas folhas. A salinidade reduziu a produção de frutos. A cultivar Meia Estaca foi mais tolerante à salinidade do que a Santa Adélia.

Palavras-chave: Salinidade, nutrição mineral, tolerância à salinidade

\begin{abstract}
Tomato (Lycopersicon esculentum Mill.) is one of the most consumed vegetables in the world. In Paraiba State, the yield is bellow the national average, and the salinity has contributed for this. This work aimed to evaluate the salinity effects in growth, plant nutrition and yield on two tomato cultivars. Santa Adelia and Meia Estaca cultivars were irrigated with saline water $\left(0.4 ; 1.5 ; 3.0 ; 3.5\right.$; and $\left.6.0 \mathrm{dS} \mathrm{m}^{-1}\right)$, in a $2 \times 5$ factorial design, with 3 replications. Shoots and roots dry matter, the relative growth rate, $\mathrm{N}, \mathrm{K}, \mathrm{Ca}, \mathrm{Mg}$, $\mathrm{S}$, and $\mathrm{Na}$ contents in the leaves, and fruits yield were analyzed. The salinity reduced shoot dry matter in Santa Adelia cultivar. Both cultivars had different behaviors related to leaf ion contents. The salinity reduced the fruit yield. Meia Estaca cultivar was more salt tolerant than Santa Adelia cultivar.
\end{abstract}

Key words: Salinity, plant nutrition, salt tolerance

\footnotetext{
${ }^{1}$ Parte da Dissertação apresentada pelo segundo autor para obtenção do grau de Mestre pela Universidade Federal da Paraíba, CCA, Campus II, Areia-PB.

${ }^{2}$ Universidade Federal de Campina Grande, Campus de Patos-PB, Av. Universitária, s/n, Bairro Santa Cecília, Patos-PB. E-mail: lofreire@cstr.ufcg.edu.br

${ }^{3}$ Empresa de Assistência Técnica e Extensão Rural, EMATER, Picuí-PB. E-mail: vpsaraiva@hotmail.com

${ }^{4}$ Universidade Federal de Campina Grande, Campus de Pombal-PB. E-mail: paesr@hotmail.com

${ }^{5}$ Universidade Federal da Paraíba, Campus II, Areia-PB. (in memorian).

* Autor para correspondência
} 


\section{Introdução}

O tomateiro (Lycopersicon esculentum Mill.) é uma das hortaliças mais consumidas no mundo e no Brasil, destacando-se entre as três mais importantes. No Estado da Paraíba a área plantada em 2006 foi de 896 ha com produção de 30.289 toneladas, correspondendo à produtividade de $36,8 \mathrm{t} \mathrm{ha}^{-1}$, e participação de $0,96 \%$ da produção nacional, com rendimento no mínimo 50\% mais baixo do que a média brasileira (IBGE, 2010). Muitos fatores contribuem para esses baixos rendimentos, dentre os quais merecem destaque algumas técnicas inadequadas de cultivo, como utilização de sementes de baixa qualidade, irrigação deficiente ou com água de má qualidade, manejo do solo nem sempre compatível com a exigência da cultura, controle inadequado de pragas e doenças e quase nenhuma proteção do solo contra as perdas hídricas por evaporação (CAVALCANTE et al., 2001).

A baixa precipitação e a alta evaporação nas regiões áridas e semi-áridas são fatores que contribuem para a ocorrência de solos salinos e sódicos, os quais representam, em termos globais, aproximadamente 900 milhões de hectares. Nessas condições, os sais não são lixiviados e acumulamse no solo e na água em quantidades prejudiciais ao crescimento normal das plantas (FAGERIA; GHEYI, 1997).

Os efeitos do sal nas plantas podem ser de natureza osmótica, restringindo a disponibilidade de água e de nutrientes; por toxicidade, com acúmulo de íons específicos, principalmente $\mathrm{Na}^{+}$e $\mathrm{Cl}^{-}$; ou por distúrbios na nutrição das plantas, refletindo diretamente no metabolismo e crescimento das plantas (SHANNON, 1997; CHUSMAN, 2001). Quando expostas à salinidade, as plantas apresentam aumento na produção de alguns tipos de oxigênio reativo, tais como oxigênio singlet $\left(1 / 2 \mathrm{O}_{2}\right)$, radical superóxido $\left(\mathrm{O}_{2}^{-}\right)$, peróxido de hidrogênio $\left(\mathrm{H}_{2} \mathrm{O}_{2}\right)$ e radical hidroxila (OH) (ASHRAF; HARRIS, 2004). Esses compostos causam danos oxidativos, como inativação enzimática, peroxidação de lipídeos, degradação de proteínas e danos no DNA (ZUSHI; MATSUZOE, 2009).

O tomateiro é considerado uma cultura moderadamente sensível à salinidade (DOORENBOS; KASSAM, 1994). No entanto, o seu cultivo em áreas com salinidade moderada tem sido empregado como alternativa para melhorar a qualidade do produto, pois, segundo Cuartero e Ferñandez-Muñoz (1999), o estresse salino promove aumento na concentração de açúcares, de ácidos orgânicos e na porcentagem de massa seca dos frutos, apesar de ocorrer redução no seu tamanho e na produção. A utilização de água com níveis moderados de salinidade tem se tornando uma prática comum, tanto devido à disponibilidade cada vez menor de água de boa qualidade, como uma estratégia para melhoria da qualidade da produção. Baseado nisso, este trabalho teve por objetivo estudar os efeitos da salinidade da água de irrigação no crescimento, na nutrição mineral e na produção de duas cultivares de tomateiro rasteiro.

\section{Material e Métodos}

O experimento foi conduzido entre dezembro de 2003 e maio de 2004, em ambiente telado com cobertura plástica, no Departamento de Fitotecnia do Centro de Ciências Agrárias da Universidade Federal da Paraíba, Campus II, município de AreiaPB, localizado pelas coordenadas geográficas $6^{\circ}$ $58^{\prime} 12$ " de latitude sul, $35^{\circ} 43$ ' 15 " de longitude oeste, e altitude $573 \mathrm{~m}$.

Utilizou-se o delineamento inteiramente casualizado, em arranjo fatorial $2 \times 5$, com 3 repetições. $\mathrm{O}$ primeiro fator correspondeu às cultivares de tomateiro rasteiro (Santa Adélia e Meia Estaca), e o segundo, a cinco níveis de salinidade da água de irrigação [0,4 (tratamento controle); 1,$5 ; 3,0 ; 4,5$ e $\left.6,0 \mathrm{dS} \mathrm{m}^{-1}\right]$, obtidos por meio de diluições de uma água salina, proveniente de açude no município de Remígio-PB, com as seguintes características: $\mathrm{pH} 7,9$; condutividade elétrica 22,6 $\mathrm{dS} \mathrm{m}{ }^{-1} ; \mathrm{Ca}^{2+} 16,10 \mathrm{mmol}_{\mathrm{c}} \mathrm{l}^{-1} ; \mathrm{Mg}^{2+} 88,92 \mathrm{mmol}_{\mathrm{c}}{ }^{-1}$; 
$\mathrm{K}^{+} 2,15 \mathrm{mmol}_{\mathrm{c}} \mathrm{1}^{-1} ; \mathrm{Na}^{+} 94,00 \mathrm{mmol}_{\mathrm{c}} \mathrm{1}^{-1} ; \mathrm{HCO}_{3}^{-} 4,20$ $\mathrm{mmol}_{\mathrm{c}} \mathrm{1}^{-1} ; \mathrm{SO}_{4}^{-1} 1,27 \mathrm{mmol}_{\mathrm{c}} \mathrm{1}^{-1} ; \mathrm{Cl}^{-} 256,87 \mathrm{mmol}_{\mathrm{c}} \mathrm{1}^{-1} \mathrm{e}$ razão de adsorção de sódio $12,50\left(\mathrm{mmol}_{\mathrm{c}} \mathrm{l}^{-1}\right)^{1 / 2}$.

As mudas foram produzidas inicialmente em canteiros e aos 20 dias após a semeadura, plantas uniformes quanto ao tamanho, com dois ou três pares de folhas definitivas, foram transplantadas para recipientes plásticos $\left(0,05 \mathrm{~m}^{2}\right)$ contendo 10 $\mathrm{kg}$ de substrato, com um vaso por repetição. Esse substrato consistiu de material coletado nos 20 cm superficiais de um solo Latossolo Vermelho Amarelo, na fazenda experimental Chã de Jardim, pertencente ao CCA/UFPB, o qual foi caracterizado física e quimicamente, apresentando $\mathrm{pH}$ 5,7; P 12,69 mg.dm ${ }^{-3} ; \mathrm{K}^{+} 63,0 \mathrm{cmol}_{\mathrm{c}} \cdot \mathrm{dm}^{-3} ; \mathrm{Ca}^{2+} 3,15 \mathrm{cmol}_{\mathrm{c}} \cdot \mathrm{dm}^{-3}$; $\mathrm{Mg}^{2+} 1,55 \mathrm{cmol}_{\mathrm{c}} \cdot \mathrm{dm}^{-3} ; \mathrm{Al} \mathrm{0,0} \mathrm{cmol}_{\mathrm{c}} \cdot \mathrm{dm}^{-3} ; \mathrm{H}+\mathrm{Al}$ 5,03 $\mathrm{cmol}_{\mathrm{c}} \cdot \mathrm{dm}^{-3}$; Soma de Bases 4,93; CTC 9,96; $\mathrm{Na}^{+}$ $0,07 \mathrm{cmol} \cdot \mathrm{dm}^{-3}$; condutividade elétrica $0,90 \mathrm{dS} \cdot \mathrm{m}^{-1}$; Matéria orgânica $30,92 \mathrm{~g} \cdot \mathrm{Kg}^{-1}$, e textura francoargilo-arenosa.

Após a análise do solo, os vasos foram adubados com $200 \mathrm{~kg} \cdot \mathrm{ha}^{-1}$ de N, $86 \mathrm{~kg} \cdot \mathrm{ha}^{-1}$ de $\mathrm{P}_{2} \mathrm{O}_{5}$ e $120 \mathrm{~kg} \cdot \mathrm{ha}^{-1}$ de $\mathrm{K}_{2} \mathrm{O}$, baseados na análise de fertilidade e exigência da cultura. Em seguida, foram distribuídos, dentro do ambiente telado, em espaçamento $1,70 \mathrm{~m} \times 0,40 \mathrm{~m}$, conforme espaçamento para a cultura recomendado pelo Instituto Agronômico de Pernambuco (IPA). A irrigação foi realizada procurando-se manter a umidade do solo próximo a $60 \%$ do volume total de poros (VTP) preenchidos com água. O VTP do solo foi calculado segundo Embrapa (1997), a partir dos valores da densidade aparente (Da) e densidade de partículas (Dp), utilizando-se a seguinte fórmula: $\mathrm{VTP}=[(\mathrm{Dp}-\mathrm{Da}) / \mathrm{Dp}] \times 100$. A irrigação foi feita diariamente pesando-se o conjunto vaso-solo-planta e colocando-se a quantidade necessária de água para atingir 60 \% do VTP. Em função do cultivo ter sido rasteiro, não houve o uso de podas ou tutoramento. No controle de pragas e doenças, adotaram-se as recomendações da Embrapa Semiárido (HAIJ et al., 1996).
Quinzenalmente após o transplante foi determinada a altura das plantas para a determinação da taxa de crescimento relativo (TCR), calculada de acordo com Benincasa (1988). Aos 120 dias após o transplante, as plantas foram cortadas e separadas em parte aérea (folhas e caule) e raízes e colocadas para secar em estufa com circulação forçada a \pm $70{ }^{\circ} \mathrm{C}$, até atingirem peso constante. Em seguida, esse material foi submetido à pesagem, para a determinação da massa seca da parte aérea e das raízes.

Após a secagem e pesagem, foram retiradas amostras foliares para as determinações dos teores de $\mathrm{N}, \mathrm{K}, \mathrm{Ca}, \mathrm{Mg}, \mathrm{S}$ e Na. Após a digestão nitroperclórica, foram determinados: os teores de $\mathrm{Ca}$ e $\mathrm{Mg}$, por espectrometria de absorção atômica; $\mathrm{K}$ por fotometria de emissão de chama, e S, por turbidimetria do sulfato de bário (MALAVOLTA; VITTI; OLIVEIRA, 1997). Para a determinação dos teores de $\mathrm{N}$ total, realizou-se a digestão pelo método semimicro Kjedahl (LIAO, 1981), sendo a destilação e a titulação efetuadas segundo Bremner e Eduards (1965).

Os resultados foram submetidos à análise de variância e de regressão através do programa estatístico SAEG (Sistema de Análises Estatísticas e Genéticas) desenvolvido pela Universidade Federal de Viçosa.

\section{Resultados e Discussão}

Não foi verificado efeito significativo dos tratamentos na massa seca das raízes e na taxa de crescimento relativo das plantas (Tabelas 1 e 2) e interação significativa entre os tratamentos em relação à massa seca da parte aérea (Tabelas 1 e 3 ). De acordo com a tabela 3 , percebe-se que houve diferença estatística entre as cultivares no tratamento controle, e que, à proporção que a salinidade aumentou, não foi observada diferença estatística entre as mesmas. 
Tabela 1. Resumo da Análise de Variância das variáveis de crescimento de plantas de duas cultivares de tomateiro irrigadas com água salina.

\begin{tabular}{|c|c|c|c|c|c|}
\hline \multirow{2}{*}{$\begin{array}{c}\text { Fontes de } \\
\text { variação }\end{array}$} & \multirow[t]{2}{*}{ GL } & \multicolumn{4}{|c|}{ Quadrado Médio } \\
\hline & & MSPA & MSR & PROD & TCR \\
\hline Variedades $(\mathrm{V})$ & 1 & $10,057^{*}$ & $13,771^{\mathrm{NS}}$ & $0,012^{\mathrm{NS}}$ & $0,006^{\mathrm{NS}}$ \\
\hline Salinidade (NS) & 4 & $3,435^{\mathrm{NS}}$ & $2,150^{\mathrm{NS}}$ & $0,058^{*}$ & $0,178^{\mathrm{NS}}$ \\
\hline $\mathrm{V} \times \mathrm{NS}$ & 4 & $6,892^{*}$ & $3,973^{\mathrm{NS}}$ & $0,003^{\mathrm{NS}}$ & $0,026^{\mathrm{NS}}$ \\
\hline \multicolumn{6}{|l|}{ NS / V1 } \\
\hline Efeito linear & 1 & $6,484^{*}$ & $8,254^{\mathrm{NS}}$ & $0,157 * *$ & $0,164^{\mathrm{NS}}$ \\
\hline Efeito quadrático & 1 & $15,256^{\mathrm{NS}}$ & $3,94^{\mathrm{NS}}$ & $0,008^{\mathrm{NS}}$ & $0,057^{\mathrm{NS}}$ \\
\hline \multicolumn{6}{|l|}{ NS / V2 } \\
\hline Efeito linear & 1 & $1,245^{\mathrm{NS}}$ & $1,058^{\mathrm{NS}}$ & $0,063^{*}$ & $0,137^{\mathrm{NS}}$ \\
\hline Efeito quadrático & 1 & $3,135^{\mathrm{NS}}$ & $8,557^{\mathrm{NS}}$ & $0,004^{\mathrm{NS}}$ & $0,048^{\mathrm{NS}}$ \\
\hline Resíduo & 20 & 1,98251 & 7,28180 & 0,01626 & 0,17241 \\
\hline $\mathrm{CV}(\%)$ & & 11,22 & 20,24 & 4,16 & 37,49 \\
\hline \multicolumn{6}{|c|}{$\mathrm{NS},{ }^{*}, * *$ = Não significativo, significativo a 5 e $1 \%$ de probabilidade, respectivamente, pelo teste $\mathrm{F}$. } \\
\hline \multicolumn{6}{|c|}{$\begin{array}{l}\text { Tabela 2. Massa seca das raízes (MSR) e taxa de crescimento relativo de plantas de tomateiro, cultivares Santa Adélia } \\
\text { e Meia Estaca, em função da salinidade da água de irrigação. (1) }\end{array}$} \\
\hline $\begin{array}{l}\text { Condutividade } \\
\text { elétrica (C.E.) }\end{array}$ & \multicolumn{3}{|c|}{$\operatorname{MSR}\left(g\right.$ planta $\left.^{-1}\right)$} & \multicolumn{2}{|c|}{$\operatorname{TCR}\left(\mathrm{cm} \mathrm{cm}^{-1} \mathrm{dia}^{-1}\right)$} \\
\hline$\left.(\mathrm{dS} \mathrm{m})^{-1}\right)$ & Santa Adélia & & Meia Estaca & Santa Adélia & Meia Estaca \\
\hline 0,4 & 6,75 & & 6,25 & 1,20 & 1,08 \\
\hline 1,5 & 6,62 & & 5,87 & 1,29 & 1,40 \\
\hline 3,0 & 6,18 & & 6,02 & 1,02 & 1,00 \\
\hline 4,5 & 6,05 & & 5,84 & 1,26 & 1,06 \\
\hline 6,0 & 6,12 & & 5,65 & 0,84 & 0,93 \\
\hline
\end{tabular}

(1) Não significativo pelo teste $F$.

Tabela 3. Massa seca da parte aérea (MSPA) de plantas de tomateiro, cultivares Santa Adélia e Meia Estaca, em função da salinidade da água de irrigação.

\begin{tabular}{ccc}
\hline $\begin{array}{c}\text { Condutividade elétrica (C.E.) } \\
\text { MSPA }\left(g \text { planta }^{-1}\right)\end{array}$ & Meia Estaca \\
\hline$\left(\mathrm{dS} \mathrm{m}^{-1}\right)$ & Santa Adélia & $11,13 \mathrm{~b}$ \\
1,4 & $15,95 \mathrm{a}$ & $11,97 \mathrm{a}$ \\
3,0 & $11,54 \mathrm{a}$ & $12,20 \mathrm{a}$ \\
4,5 & $12,09 \mathrm{a}$ & $13,03 \mathrm{a}$ \\
6,0 & $13,28 \mathrm{a}$ & $11,53 \mathrm{a}$ \\
\hline
\end{tabular}

Médias seguidas de letras iguais, nas linhas, não diferem estatisticamente entre si pelo teste de Tukey $(\mathrm{P} \leq 0,05)$. 
Em relação os efeitos da salinidade na massa seca da cultivar Santa Adélia (Figura 1a), nota-se redução linear com o aumento da salinidade da água de irrigação, chegando a aproximadamente $17 \%$ quando se compara o tratamento controle com o nível de salinidade mais alto. Na cultivar Meia Estaca, não houve efeito significativo dos tratamentos de salinidade, indicando que essa cultivar foi indiferente

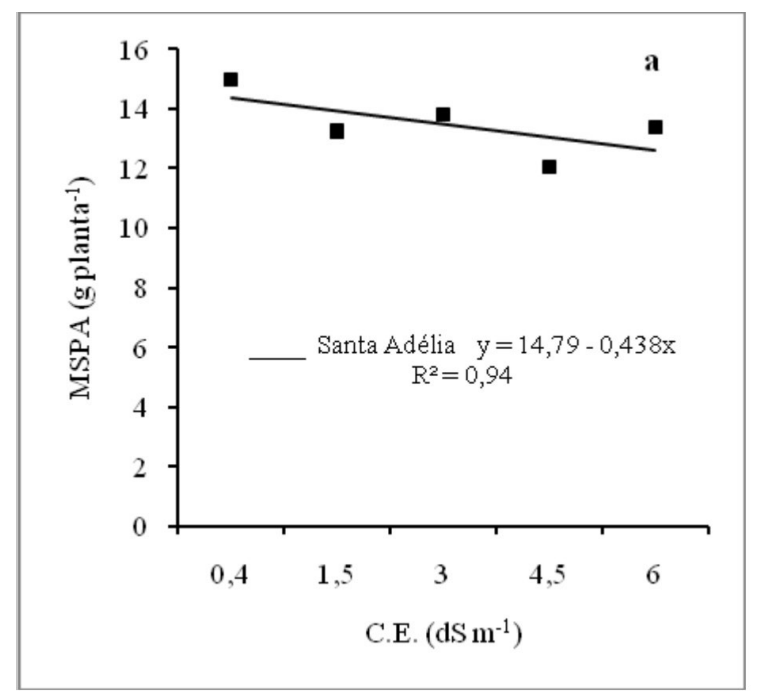

ao estresse salino. Comportamento diferencial entre cultivares sugere variação genotípica e, conforme afirmaram Agong et al. (2003), a habilidade de um genótipo não apresentar diminuição extrema na produção de biomassa sob salinidade pode ser um critério importante para a avaliação da tolerância à salinidade.

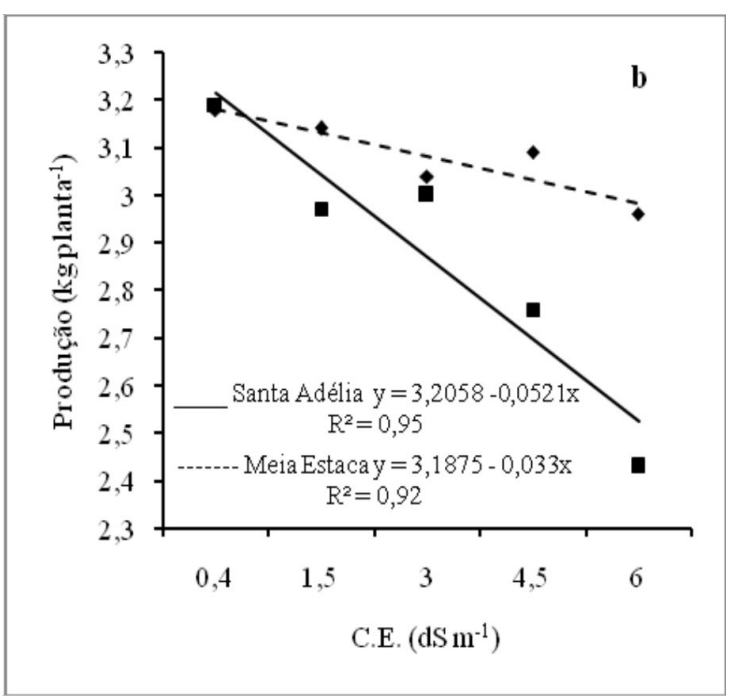

Figura 1. Massa seca da parte aérea (a) e produção de frutos de tomateiro (b) cultivares Santa Adélia e Meia Estaca em função da salinidade da água de irrigação.

$O$ fato de não ter sido verificado efeito significativo da salinidade em relação à massa seca de raízes pode indicar que, mesmo sob condições salinas, essas plantas foram capazes de produzir um sistema radicular comparável ao das plantas do tratamento controle. Esses resultados concordam com os obtidos por Agong et al. (2003) e Campos et al. (2007), os quais verificaram que a salinidade não afetou a massa seca de raízes de plantas de tomateiro. Em relação à parte aérea, Oliveira et al. (2007) e Campos et al. (2007) observaram que aumento na salinidade da água de irrigação causou reduções nos parâmetros de crescimento analisados.

O estresse hídrico, induzido pela concentração salina, reduz o crescimento, não apenas pelos seus efeitos na assimilação de $\mathrm{CO}_{2}$, mas também pela redução da taxa de divisão e de alongamento celulares. Esse estresse causa redução na pressão de turgescência em virtude da diminuição do conteúdo de água, resultando em declínio na expansão da parede celular, menor crescimento e baixa produção de matéria seca (PUGNAIRE; ENDOLZ; PARDOS, 1993).

Estresse salinoacarreta mudanças no crescimento, na morfologia e na fisiologia das raízes, interferindo na absorção de água e de íons. Sendo assim, toda a planta é então afetada quando as raízes estão crescendo em meio salino. Redução na biomassa de raízes de tomateiro em virtude da salinidade foi verificada por Papadopoulos e Rendig (1983), os quais verificaram que o limite superior de tolerância, em que aumento da salinidade causa redução no crescimento das raízes foi $4 \mathrm{dS} \mathrm{m}^{-1}$. Várias são as razões pelas quais o estresse salino causa redução no crescimento das raízes, dentre os quais restrição ao crescimento celular, interferência dos sais na nutrição vegetal ou a toxicidade de íons acumulados, levando à morte das células (CUARTERO; 
FERNÁNDEZ-MUÑOZ, 1999). No entanto, não se pode desconsiderar a possibilidade da restrição à expansão celular se constituir em ajustamento necessário em ambientes salinos (BENZIL et al., 1989). Pérez-Alfocea et al. (1996) mostraram que plantas crescidas em ambiente salino apresentaram maior proporção de assimilados nas raízes, em relação à parte aérea, quando comparadas com as plantas controle, mostrando que as raízes são menos afetadas pela salinidade do que a parte aérea.

A salinidade exerceu efeito significativo na produção de frutos por planta (Tabela 1). A produção de frutos de ambas as cultivares diminuiu linearmente com o aumento da salinidade da água de irrigação (Figura 1b). Na cultivar Santa Adélia, a redução da produção foi de $10,0 \%$, enquanto que na cultivar Meia Estaca, foi de 6,78\%, quando se compara o controle com o mais alto nível de salinidade da água de irrigação, o que significa redução de 0,29 $\mathrm{kg}_{\text {planta }}{ }^{-1}$ (4,26 t/ha) e $0,18 \mathrm{~kg}$ planta $^{-1}(2,64 \mathrm{t} / \mathrm{ha})$, respectivamente. As produções por planta obtidas estão próximas da média nacional que é de $3,5 \mathrm{~kg} /$ planta, segundo Santos, Pereira e Freire (2001).

Redução na produção de frutos em função da salinidade foi observada por Cuartero e Fernández-
Muñoz (1999), Campos et al. (2006), Campos et al. (2007) e Oliveira et al. (2007). De acordo com Castellane (1983), a salinidade causa redução da produtividade da cultura, principalmente no peso médio dos frutos. González-Fernández e Cuartero (1993) observaram que irrigações com água cuja $\mathrm{CE}$ foi de 5 a $6 \mathrm{dS} \mathrm{m}^{-1}$ causou reduções de $10 \%$ no peso do fruto, de $30 \%$ quando utilizaram água com CE $8 \mathrm{dS} \mathrm{m}^{-1}$ e em torno de $40 \%$ em CE superiores a esse valor.

A produção de tomate pode ser diminuída pelo decréscimo no peso médio do fruto e/ou redução de número de frutos por planta. Sob CE relativamente baixa, Ehret e Ho (1986) verificaram que a queda na produção foi causada principalmente pela redução no peso médio dos frutos, enquanto o número de frutos ficou inalterado. Por outro lado o declínio no número de frutos foi considerado, por Ieperen (1996) e Cuartero e Soria (1997) como a principal causa na redução na produção sob altas CE.

Não houve efeito significativo dos tratamentos nos teores foliares de $\mathrm{N}$ e S (Tabela 4) e, para os demais nutrientes analisados, os efeitos foram diferentes, de acordo com a cultivar estudada (Tabelas 4 e 5).

Tabela 4. Resumo da Análise de Variância para os teores foliares de nutrientes em duas cultivares de tomateiro irrigadas com água salina.

\begin{tabular}{|c|c|c|c|c|c|c|c|}
\hline \multirow{2}{*}{$\begin{array}{l}\text { Fontes de } \\
\text { variação }\end{array}$} & \multirow[t]{2}{*}{ GL } & \multicolumn{6}{|c|}{ Quadrado Médio } \\
\hline & & $\mathrm{N}$ & K & $\mathrm{Ca}$ & $\mathrm{Mg}$ & $\mathrm{S}$ & $\mathrm{Na}$ \\
\hline Variedades (V) & 1 & $44,65^{\mathrm{NS}}$ & $55,49 *$ & $49,22 *$ & $42,65^{\mathrm{NS}}$ & $0,843^{\mathrm{NS}}$ & $0,147^{\mathrm{NS}}$ \\
\hline Salinidade (S) & 4 & $25,932^{\mathrm{NS}}$ & $30,82^{\mathrm{NS}}$ & $26,59^{\mathrm{NS}}$ & $69,32^{\mathrm{NS}}$ & $0,554^{\mathrm{NS}}$ & $179,10 * *$ \\
\hline $\mathrm{V} \times \mathrm{S}$ & 4 & $13,56^{\mathrm{NS}}$ & $4,878^{\mathrm{NS}}$ & $14,429^{\mathrm{NS}}$ & $7,732^{\mathrm{NS}}$ & $0,044^{\mathrm{NS}}$ & $21,365^{\mathrm{NS}}$ \\
\hline \multicolumn{8}{|l|}{$\mathrm{S} / \mathrm{V} 1$} \\
\hline Efeito linear & 1 & $7,505^{\mathrm{NS}}$ & $41,82^{\mathrm{NS}}$ & $49,670^{\mathrm{NS}}$ & $120,71 *$ & $1,116^{\mathrm{NS}}$ & $294,98 *$ \\
\hline Efeito quadrático & 1 & $52,51^{\mathrm{NS}}$ & $0,095^{\mathrm{NS}}$ & $23,375^{\mathrm{NS}}$ & $20,99^{\mathrm{NS}}$ & $0,079^{\mathrm{NS}}$ & $0,622^{\mathrm{NS}}$ \\
\hline \multicolumn{8}{|l|}{$\mathrm{S} / \mathrm{V} 2$} \\
\hline Efeito linear & 1 & $3,68^{\mathrm{NS}}$ & $73,387^{*}$ & $79,45^{*}$ & $14,71^{\mathrm{NS}}$ & $0,466^{\mathrm{NS}}$ & $364,29 *$ \\
\hline Efeito quadrático & 1 & $0,04^{\mathrm{NS}}$ & $5,941^{\mathrm{NS}}$ & $23,37^{\mathrm{NS}}$ & $6,84^{\mathrm{NS}}$ & $0,042^{\mathrm{NS}}$ & $58,75^{\mathrm{NS}}$ \\
\hline Resíduo & 20 & 29,36 & 11,48 & 20,05 & 33,34 & 0,38 & 20,79 \\
\hline $\mathrm{CV}(\%)$ & & 36,37 & 31,73 & 19,40 & 75,02 & 13,41 & 56,22 \\
\hline
\end{tabular}

$\mathrm{NS}, *, * *=$ Não significativo, significativo a 5 e $1 \%$ de probabilidade, respectivamente, pelo teste $\mathrm{F}$.

$\mathrm{N}=$ nitrogênio, $\mathrm{K}$ = potássio, $\mathrm{Ca}=$ cálcio, $\mathrm{Mg}=$ magnésio, $\mathrm{S}=$ enxofre, $\mathrm{Na}=$ sódio. 
Tabela 5. Teores de N, Ca, Mg e S nas folhas de plantas de tomateiro, cultivares Santa Adélia e Meia Estaca, em função da salinidade da água de irrigação. (2)

\begin{tabular}{ccccccc}
\hline C.E. & \multicolumn{2}{c}{$\mathrm{N}\left(\mathrm{g} \mathrm{kg}^{-1}\right)$} & $\mathrm{Ca}\left(\mathrm{g} \mathrm{kg}^{-1}\right)$ & \multicolumn{2}{c}{$\mathrm{Mg}\left(\mathrm{g} \mathrm{kg}^{-1}\right)$} & \multicolumn{2}{c}{$\mathrm{S}\left(\mathrm{g} \mathrm{kg}^{-1}\right)$} \\
$\left(\mathrm{dS} \mathrm{m}{ }^{-1}\right)$ & Santa Adélia & Meia Estaca & Santa Adélia & Meia Estaca & Santa Adélia & Meia Estaca \\
\hline 0,4 & 8,76 & 7,89 & 15,23 & 6,51 & 0,06 & 0,04 \\
1,5 & 9,37 & 8,42 & 16,38 & 6,22 & 0,04 & 0,02 \\
3,0 & 9,68 & 8,37 & 16,82 & 6,42 & 0,03 & 0,03 \\
4,5 & 9,82 & 8,35 & 16,78 & 5,97 & 0,05 & 0,04 \\
6,0 & 10,27 & 8,12 & 17,46 & 6,51 & 0,04 & 0,03 \\
\hline
\end{tabular}

(2) Não siginificativo pelo teste $\mathrm{F}$.

Também não foi verificada interação significativa entre os tratamentos nos teores foliares dos nutrientes (Tabela 4). Em relação ao potássio, o teor em ambas as cultivares aumentou linearmente com a elevação da salinidade, sendo os maiores valores observados na cultivar Santa Adélia. Apesar disso, a cultivar Meia Estaca apresentou aumento de $115 \%$, enquanto que, na cultivar Santa Adélia, esse aumento foi de $55 \%$, comparando-se o tratamento controle com o mais alto nível de salinidade da água de irrigação. Esse acúmulo pode ter proporcionado regulação osmótica das plantas da cultivar Meia Estaca suficiente para garantir o acúmulo de massa seca na parte aérea, uma vez que a salinidade não exerceu efeito significativo sobre a mesma, mantendo um valor médio de 11,87 g planta $^{-1}$ (Tabela 3). Este resultado mostra que a salinidade não causou efeitos negativos na absorção desse nutriente, e contrariamente, estimulou sua absorção. Os resultados obtidos diferem dos verificados por outros pesquisadores (PRIOR; GREIVE; CULLIS, 1992; MIRANDA, 2000; IRSHAD et al., 2002; DANTAS et al., 2006), os quais verificaram redução nos teores de $\mathrm{K}$ com aumento da salinidade. Em ambiente salino com alta concentração de sódio as plantas conseguem regular a absorção de potássio devido sua capacidade seletiva, absorvendo grande quantidade, normalmente requerida pelas plantas, sendo de fundamental importância na redução dos efeitos salinos sobre as plantas, por se tratar do principal componente do ajustamento osmótico (REGGIANI; BOZO; BERTANI, 1995), do qual dependem a manutenção do turgor das células e a continuidade dos processos de divisão e alongamento celulares, além da produção vegetal em ambiente salino (YEO, 1983). As células do córtex da raiz, por meio de suas membranas, têm alta afinidade pelo transporte de potássio, sendo que esse grau de seletividade pode variar drasticamente de acordo com a espécie (GRATTAN; GRIEVE, 1993). No caso de algumas não-halófitas, parte do potássio pode ser substituída pelo sódio, havendo estímulo ao crescimento, como ocorre em algumas plantas da família Chenopodiaceae; e existem plantas - como o milheto, a cevada, o arroz e o tomate - em que o potássio pode ser substituído pelo sódio apenas em pequena proporção, e o sódio não exerce efeito específico no crescimento (FURLANI, 2004).

Não houve efeito significativo da salinidade no teor de cálcio da cultivar Santa Adélia (Tabela 2). Na cultivar Meia Estaca (Figura 2a), o teor de cálcio aumentou com aumento da salinidade da água de irrigação, com comportamento quadrático, sendo que o teor máximo foi obtido na $\mathrm{CE} 3,0 \mathrm{dS} \mathrm{m} \mathrm{m}^{-1}$, reduzindo até o nível de $6,0 \mathrm{dS} \mathrm{m}^{-1}$. Redução nos teores foliares de cálcio sob condições de salinidade foram verificados por Miranda (2000) e Silva Filho et al. (2000), enquanto Dantas et al. (2006) observaram o contrário. Níveis de salinidade acima de CE 3,0 dS m$~^{-1}$ podem ter reduzido o influxo de cálcio para as raízes, afetando a troca cationica no apoplasto, conforme afirmam Grattan e Grieve (1993), pois a salinidade elevada pode causar a substituição do cálcio pelo potássio, sódio ou $\mathrm{H}^{+}$nas membranas das raízes (FURLANI, 2004). Percebese que quando a concentração cálcio nas plantas reduziu (Figura 2b) as de potássio (Figura 2a) e de sódio (Figura 2d) permaneciam elevados. 

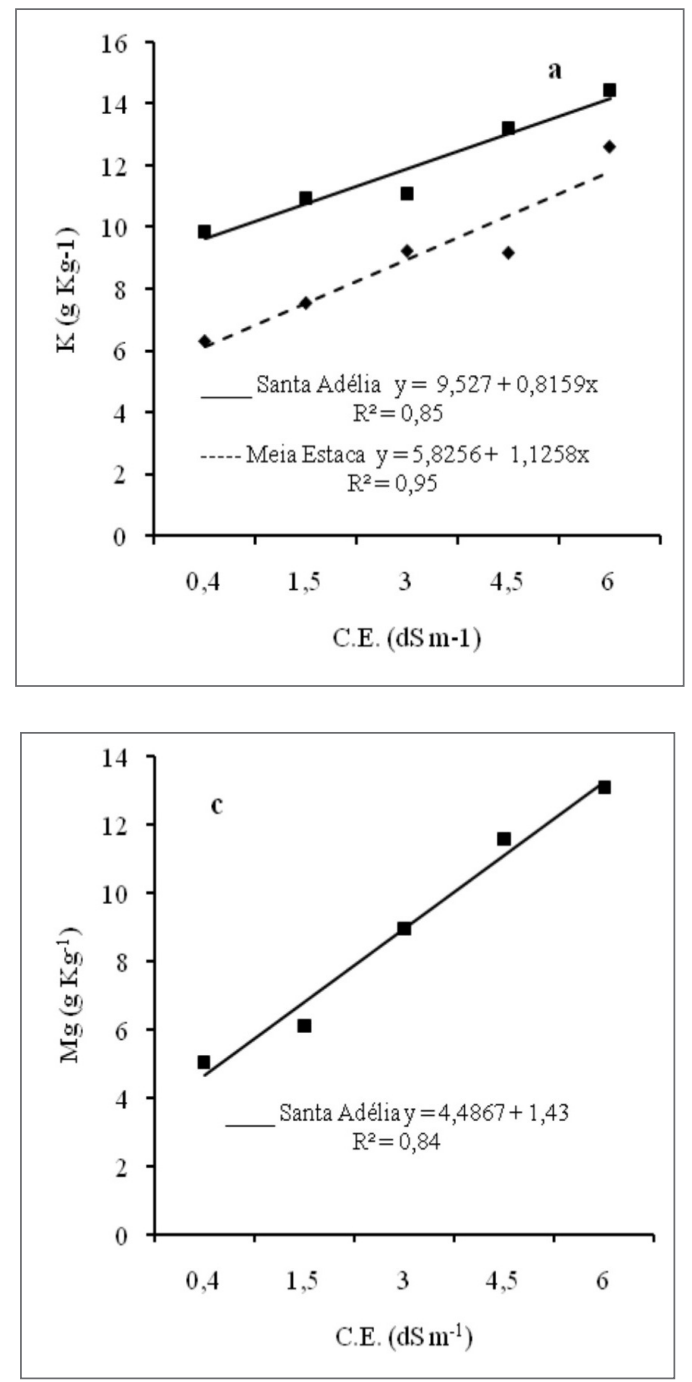

Figura 2. Teores foliares de $\mathrm{K}^{+}(\mathrm{a}), \mathrm{Ca}^{2+}(\mathrm{b}), \mathrm{Mg}^{2+}$ (c) e $\mathrm{Na}^{+}$(d) em plantas de tomateiro, cultivares Santa Adélia e Meia Estaca, em função da salinidade da água de irrigação.

O teor de magnésio na cultivar Santa Adélia (Figura 2c) aumentou à medida que os níveis de salinidade aumentaram, seguindo equação linear. $\mathrm{Na}$ cultivar Meia Estaca não houve alteração no teor de magnésio mesmo com o aumento da salinidade, mantendo-se constante em $6,51 \mathrm{~g} \mathrm{Kg}^{-1}$. Esses resultados concordam com os obtidos por Prior, Greive e Cullis (1992) e Dantas et al. (2006), os quais não observaram variações nos teores de magnésio nas folhas. No entanto, diferem dos obtidos por Datta et al. (1995), que verificaram redução com aumento da salinidade. O magnésio exerce funções importantes na célula vegetal,
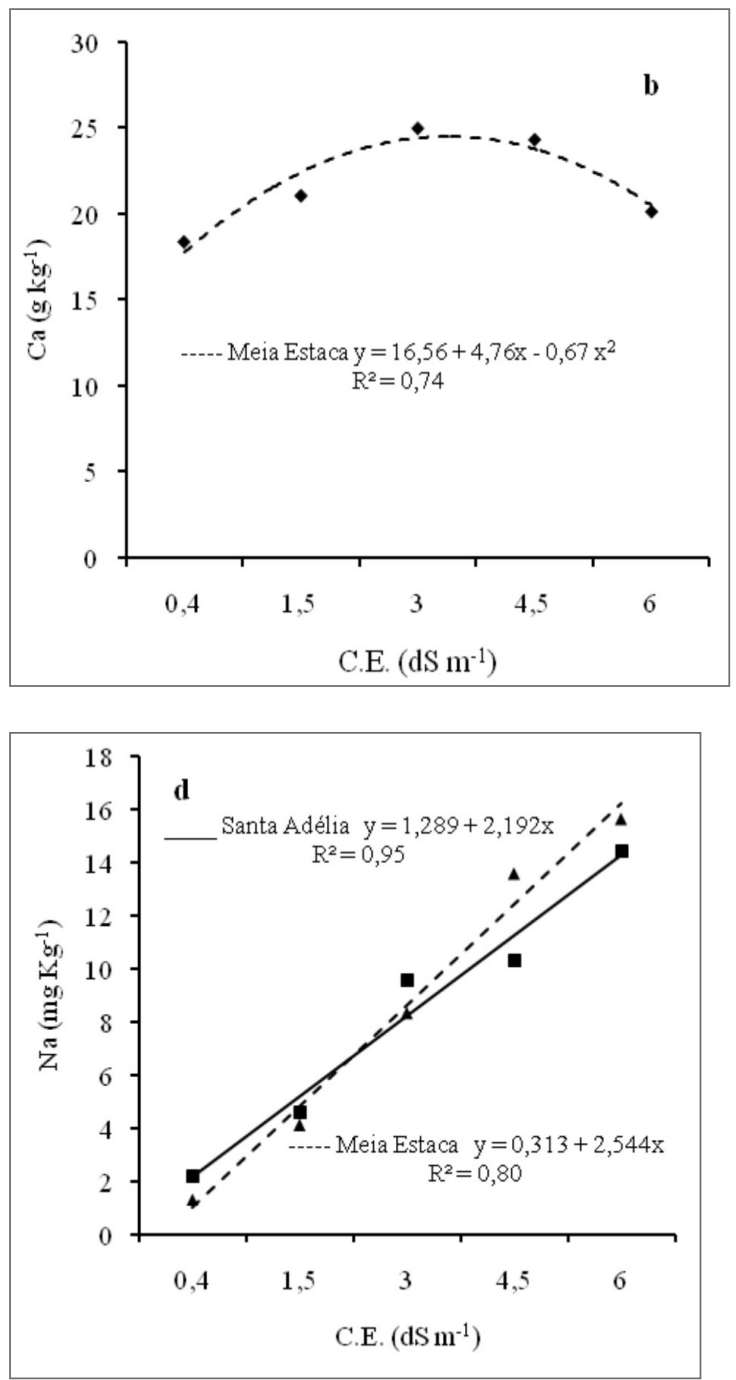

que vão desde a síntese de proteínas e clorofilas, ativação enzimática, fosforilação, fotossíntese, até a partição de carbono no tecido vegetal, uma vez que, em plantas deficientes em magnésio, a queda na capacidade fotossintética altera o suprimento de fotoassimilados, alterando as relações fonte/dreno (MARSCHNER, 1995).

Percebe-se que houve efeito diferenciado da salinidade nas cultivares quanto ao cálcio e magnésio (Tabelas 4). Em virtude de haver, entre esses nutrientes, antagonismo na absorção (LIMA et al., 1981), nota-se que enquanto um nutriente 
apresentou aumento no teor com a salinidade, o outro não sofreu influência significativa. No entanto, os teores de cálcio e magnésio obtidos nesse estudo (Tabela 5; Figuras 2b, 2c) estão dentro dos limites considerados pela Embrapa (1994) como adequados para a cultura do tomateiro, que são $15-30 \mathrm{~g} \mathrm{~kg}^{-1} \mathrm{e}$ $4-6 \mathrm{~g} \mathrm{~kg}^{-1}$, respectivamente.

Houve aumento do teor de sódio com o aumento da salinidade pela água de irrigação, seguindo equação linear, em ambas as cultivares (Figura 2d), evidenciando que essas plantas não foram eficientes em evitar a absorção e translocação desse íon para as folhas das plantas. O aumento no teor de sódio foi maior na cultivar Meia Estaca, quando se compara o tratamento controle com maior nível de salinidade da água de irrigação. O sódio aumenta a porosidade das membranas (RENGEL, 1992), resultando na sua despolarização (CACHORRO; OTIZ; CERDÁ, 1994). Portanto, em meio salino, a absorção deste elemento pode não ser inibida, e sua alta concentração no meio pode afetar o transporte de cálcio para as raízes, alterando a estabilidade e a seletividade das membranas na absorção de íons (ASHRAF; O’LEARY, 1997). O sódio exerce ainda efeito negativo no ambiente celular, através dos efeitos tóxicos, em diversas reações enzimáticas e uma inadequada compartimentação desse elemento entre citoplasma e vacúolo leva à desidratação e consequente diminuição da turgescência da célula, o que pode provocar morte celular em folhas e ramos e consequente senescência (MARSCHNER, 1995).

Apesar de o sódio substituir o potássio no ajustamento osmótico vacuolar, o mesmo parece não ocorrer com a geração de turgor nos estômatos, o que, presumivelmente, reflete a operação de um transporte específico e direcional de íons altamente seletivos para o potássio. A seletividade do sistema de transporte de potássio sobre o sódio fornece uma limitação fundamental no grau em que o sódio substituirá o potássio nas plantas e o aparente requerimento de potássio para a exclusão de sódio. Essa variação pode resultar na elevação do sódio citoplasmático e, também, por conseqüência do vacuolar e do transportado para o xilema (FLOWERS; LAUCHLI, 1983).

As duas cultivares estudadas apresentaram redução na produção de frutos (Figura 1b), mas, apesar de não ter sido observada diferença entre as cultivares, esse efeito negativo da salinidade da água de irrigação foi menos acentuado na cultivar Meia Estaca. Tal comportamento pode ser uma indicação de maior habilidade dessas plantas em se ajustar osmoticamente, pois, mesmo que o aumento na absorção do sódio da cultivar Meia Estaca $(4.880 \%)$ tenha sido maior do que o da cultivar Santa Adélia (1.000\%) (Figura 2d), o aumento no teor de $\mathrm{K}$ também foi maior (115\% contra $55 \%$ da cultivar Santa Adélia) (Figura 2a), quando a CE da água de irrigação elevou-se 0,4 para $6,0 \mathrm{dS} \mathrm{m}^{-1}$. Esses acúmulos podem ter proporcionado a essas plantas condições para que mantivessem o potencial hídrico em níveis que permitissem a manutenção do crescimento e produção. Isto mostra que essa cultivar foi mais tolerante à salinidade do que a cultivar Santa Adélia, evidenciando a variabilidade genética existente entre as mesmas.

\section{Conclusões}

A salinidade reduziu a massa seca da parte aérea nas plantas da cultivar Santa Adélia. As cultivares apresentaram comportamento diferenciado quanto aos teores de nutrientes nas folhas em função da salinidade da água de irrigação. A produção de frutos foi prejudicada pela salinidade da água de irrigação. A cultivar Meia Estaca apresentou-se mais tolerante à salinidade.

\section{Agradecimentos}

À Coordenação de Aperfeiçoamento de Pessoal de Ensino Superior - CAPES, pela concessão da bolsa de estudos. 


\section{Referências}

AGONG, S. G.; KINGETSU, M.; YOSHIDA, Y.; YAZAWA, S.; MATSUDA, M. Response of tomato genotypes to induced salt stress. African Crop Science Journal, Uganda, v. 11, n. 2, p. 133-142, 2003.

ASHRAF, M.; HARRIS, P. J. C. Potential biochemical indicators of salinity tolerance in plants. Plant Science, Logan, v. 166, n. 1, p. 3-16, 2004.

ASHRAF, M.; O'LEARY, J. W. Responses of a salttolerant and $\mathrm{s}$ salt-sensitive line of sunflower to varying sodium/calcium ratios in saline sand culture. Journal of Plant Nutrition, New York, v. 20. n. 2/3, p. 361-377, 1997.

BENINCASA, M. M. P. Análise de crescimento de plantas. Jaboticabal: FUNEP, 1988. $42 \mathrm{p}$.

BENZIL, M. L.; HASEGAWA, P. M.; HANDA, A. K.; BRESSAN, R. A. Adaptation of tobacco cells to $\mathrm{NaCl}$. Plant Physiology, Rocksville, v. 79, n. 1, p. 118-125, 1989.

BREMNER, J. M.; EDWARDS, A. P. Determination and isotope-ratio analysis of different forms of nitrogen in soils. I. Apparatus and procedure for distillation and determination of ammonium. Soil Science Society of American Proceedings, Madison, v. 29, p. 504-507, 1965.

CACHORRO, P.; OTIZ, A.; CERDÁ, A. Implications of calcium nutrition on the response of Phaseolus vulgaris L. to salinity. Plant and Soil, Dordrecht, v. 159, n. 2, p. 205-212, 1994.

CAMPOS, C. A. B.; FERNANDES, P. D.; GHEYI, H. R.; BLANCO, F. F. Tomato growth and dry matter partitioning as a function of the irrigation water quality. Revista Ciência Agronômica, Fortaleza, v. 38, n. 3, p. 239-246, 2007.

CAMPOS, C. A. B.; FERNANDES, P. D.; GHEYI, H. R.; BLANCO, F. F.; GONÇALVES, C. B.; CAMPOS, S. A. F. Yield and fruit quality of industrial tomato under saline irrigation. Scientia Agricola, Piracicaba, v. 63, n. 2, p. 146-152, 2006.

CASTELlane, P. D. Nutrição mineral do tomateiro (Lycopersicum esculentum Mill): tolerância ao Al, ao $\mathrm{Mg}$ e à salinidade, e eficiência na utilização de nutrientes In: HEREDIA, M. C. V.; CASALI, V. W. D. (Org.). Seminários de olericultura, Viçosa, 1983, v. 8, p. 96-116.

CAVALCANTE, L. F.; SANTOS, C. J. O.; CAVALCANTE, I. H. L.; FEITOSA FILHO, J. C. ZANINI, J. R. Qualidade de água para irrigação e fertirrigação. Areia: UFPB, 2001. 17 p. (Boletim Técnico Científico, n. 7).
CHUSMAN, J. C. Osmoregulation in plants: implications for agriculture. American Zoologist, Oxford, v. 41, n. 4, p. 758-769, 2001.

CUARTERO, J.; FERNANDEZ-MUNÕZ, R. Tomato and salinity. Scientia Horticulturae, Amsterdan, v. 78, n. 1/4, p. 83-125, 1999.

CUARTERO, J.; SORIA, T. Productividad de tomates cultivados en condiciones salinas. Actas de Horticultura, Córdoba, v. 16, p. 214-221, 1997.

DANTAS, J. A.; BEZERRA NETO, E.; BARRETO, L. P.; SANTOS, M. V. F. Efeito da salinidade sobre o crescimento e composição mineral de seis clones de Pennisetum. Revista Ciência Agronômica, Fortaleza, v. 37, n. 1, p. 97-101, 2006.

DATTA, K. S.; KUMAR, A.; VARMA, S. K; ANGRISH, R. Differentiation of chloride and sulphate salinity on the basis of ionic distribution in genetically diverse cultivars of wheat. Journal of Plant Nutrition, New York, v. 18, n. 10, p. 2199-2212, 1995.

DOORENBOS, J.; KASSAM, A. H. Efeito da água no rendimento das culturas. Campina Grande: UFPB, 1994. 306 p. (Estudos da FAO. Irrigação e Drenagem, 33).

EHRET, D. L.; HO, L. C. The effects of salinity on dry matter partitioning and fruit growth in tomatoes grown in nutrient film culture. Journal of Horticultural Science, Ashford, v. 61, n. 3, p. 361-367, 1986.

EMPRESA BRASILEIRA DE PESQUISA AGROPECUÁRIA - EMBRAPA. Cultivo de tomate (Lycopersicon esculentum Mill.) para industrialização. Brasília: EMBRAPA-CNPH, 1994. 36 p. (Instruções Técnicas da Embrapa Hortaliças, 12).

EMPRESA BRASILEIRA DE PESQUISA AGROPECUÁRIA - EMBRAPA. Manual de métodos de análises de solo. 2.ed. Rio de Janeiro, Ministério da Agricultura e do Abastecimento, 1997. 212 p.

FAGERIA, N. K.; GHEYI, H. R. Melhoramento genético das culturas e seleção de cultivares. In: GHEYI, H. R.; QUEIROZ, J. E.; MEDEIROS, J. F. (Ed.). Manejo e controle da salinidade na agricultura. Campina Grande: UFPB, 1997. p. 363-383.

FLOWERS, T. J.; LAUCHLI, A. Inorganic plant nutrition. New York: Springer-Verlag, 1983. 681 p.

FURLANI, A. M. C. Nutrição mineral. In: KERBAUY, G. B. (Ed.). Fisiologia vegetal. Rio de Janeiro: Guanabara Koogan, 2004. p. 40-75.

GONZÁLEZ-FERNÁNDEZ, J. J.; CUARTERO, J. Evolución de la producción de cuatro entradas de tomate cultivadas con sal. Actas de Horticultura, Córdoba, v. 10, p. 1067-1072, 1993. 
GRATTAN, S. R.; GRIEVE, C. M. Mineral nutrient acquisition and response by plants grown in saline environments. In: PESSARAKLI, P. (Ed.). Handbook of plant and crop stress. New York: Marcel Dekker, 1993. p. 203-225.

HAIJ, F. N. P.; LIMA, M. F.; TAVARES, S. C. C. H.; ALENCAR, J. A.; PREZOTTI, L. Recomendações fitossanitárias para a cultura do tomate industrial nos perímetros irrigados do Submédio São Francisco - Ano agrícola 1996. Petrolina: Embrapa-CPATSA. 1996. 8 p. (Comunicado Técnico, 65).

IEPEREN, W. V. Effects of different day and night salinity levels on vegetative growth, yield and quality of tomato. Journal of Horticultural Science, Ashford, v. 71, n. 1, p. 99-111, 1996.

INSTITUTO BRASILEIRO DE GEOGRAFIA E ESTATÍSTICA-IBGE. Estatística da produção agrícola. Brasília: IBGE. 2010. Disponível em: <http://www.ibge. gov.br/home/estatistica/indicadores/ agropecuaria/lspa/ default.shtm >. Acesso em: 01 abr. 2010.

IRSHAD, M.; YAMAMOTO, S.; ENEJI, A. E.; ENDO, T.; HONNA, T. Urea and manure effect on growth and mineral contents of maize under saline conditions. Journal of Plant Nutrition, New York, v. 25, n. 1, p. 189200, 2002.

LIAO, C. F. H. Devarda's alloy method for total nitrogen determination. Soil Science Society of American Journal, Madison, v. 45, n. 3, p. 852-855, 1981.

LIMA, J. A.; DEFELIPO, B. V.; NOVAIS, R. F.; THIÉBAUT, J. T. L. Efeitos das relações $\mathrm{Ca} / \mathrm{Mg}$ e $(\mathrm{Ca}+\mathrm{Mg}) / \mathrm{K}$ na correção da acidez de dois latossolos e na produção de matéria seca do tomateiro (Lycopersicon esculentum Mill) cv Kada. Revista Ceres, Viçosa, MG,v. 28, n. 156, p. 103-115, 1981.

MALAVOLTA, E.; VITTI, G. C.; OLIVEIRA, S. A. Avaliação do estado nutricional das plantas: princípios e aplicações. 2 .ed. Piracicaba: POTAFOS, 1997. 319 p.

MARSCHNER, H. Mineral nutrition of higher plants. 2. ed. San Diego: Academic Press, 1995. 680 p.

MIRANDA, J. R. P. Silício e cloreto de sódio na nutrição mineral e produção de matéria seca de clones de cajueiro anão-precoce (Anacardium accidentale $L$ ) e de moringa (Moringa oleifera Lam.). 2000. Tese (Doutorado em Agronomia) - Departamento de Ciência do Solo. Universidade Federal de Lavras, Lavras.

OLIVEIRA, B. C.; CARDOSO, M. A. A.; OLIVEIRA, J. C.; OLIVEIRA, F. A.; CAVALCANTE, L. F. Características produtivas do tomateiro submetido a diferentes níveis de sais, na água de irrigação. Revista Brasileira de Engenharia Agrícola e Ambiental, Campina Grande, v. 11, n. 1, p. 11-16, 2007.

PAPADOPOULOS, I.; RENDIG, V.V. Interactive effects of salinity and nitrogen on growth and yield of tomato plants. Plant and Soil, Dordrecht, v. 73, n. 1, p. 47-57, 1983.

PÉREZ-ALFOCEA, F.; BALIBREA, M. E.; SANTA CRUZ, A.; ESTAÑ, M. T. Agronomical and physiological characterization of salinity tolerance in a commercial tomato hybrid. Plant and Soil, Dordrecht, v. 180, n. 2, p. 251-257, 1996.

PRIOR, L. D.; GREIVE, A. M.; CULLIS, B. R. Sodium chloride and soil texture interactions in irrigated field growth sultana grapevines: II. Plant mineral content, growth and physiology. Australian Journal of Agricultural Research, Melbourne, v. 43, n. 12, p. 10511066, 1992.

PUGNAIRE, F. I.; ENDOLZ, L. S.; PARDOS, J. Constrains by water stress on plant growth. In: PESSARAKLI, P. (Ed.). Handbook of plant and crop stress. New York: Marcel Dekker, 1993. p. 247-259.

REGGIANI, R.; BOZO, S.; BERTANI, A. The effect of salinity on early seedling growth of seeds of three wheat (Triticum aestivum L.) cultivars. Canadian Journal of Plant Science, Ottawa, v. 75, n. 1, p. 175-177, 1995.

RENGEL, Z. Role of calcium in salt toxicity. Plant, Cell and Environment, Oxford, v. 15, n. 6, p. 625-632, 1992.

SANTOS, P. R. Z.; PEREIRA, A. S.; FREIRE, C. J. S. Cultivar e adubação NPK na produção de tomate salada. Horticultura Brasileira, Brasília, v. 19, n. 1, p. 35-39, 2001.

SHANNON, M. C. Adaptation of plants of salinity. Advances in Agronomy, San Diego, v. 60, n. 1, p. 75-120, 1997.

SILVA FILHO, S. B. da.; CAVALCANTE, L. F.; OLIVEIRA, F. A. de.; LIMA, E. M.; COSTA, J. R. M. Monitoramento da qualidade da água e acúmulo de sais no solo pela irrigação. Irrigação, Botucatu, v. 5 , n. 2, p. 122-125, 2000.

YEO, A. R. Salinity resistance: physiologies and prices. Physiologia Plantarum, Copenhagen, v. 58, n. 2, p. 214222, 1983.

ZUSHI, K.; MATSUZOE, N. Seasonal and cultivar differences in salt-induced changes in antioxidant system in tomato. Scientia Horticulturae, Amsterdan, v. 120, n. 2, p. 181-187, 2009. 
